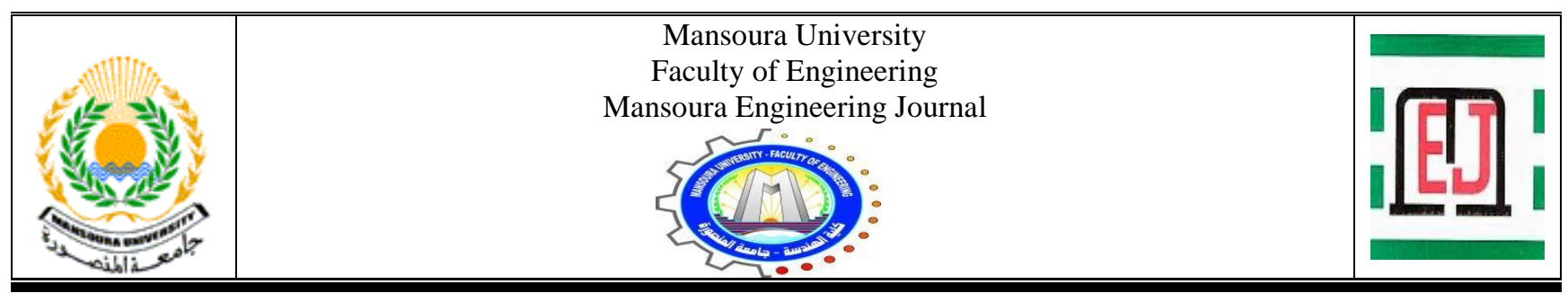

\title{
Safe pedestrian crossings as a tool to raise the quality of life for urban areas (A case study on Al-Haram st.)
}

\author{
Ahmed Mahmoud Nagi* and Dalia Shalaby Eldamaty
}

\begin{tabular}{|l|}
\hline KEYWORDS: \\
Pedestrian behavior, \\
pedestrian crossings, \\
bridges, tunnels, vertical \\
crossings, traffic culture \\
\end{tabular}

Abstract-Pedestrians are the basic nucleus that uses the road, but interest in
them did not emerge as a major indicator in the planning and design processes,
and the study gave high focus on pedestrian behavior and how they deal with
their crossings as the most important equipment that provides a safe and
comfortable environment for pedestrian traffic, and the efficiency of the
crossings And its importance in preventing pedestrian traffic from interfering
with vehicle traffic and the extent of its respect for the behavioral aspect of the
planning process. Al-Haram Street suffers from traffic problems with regard to
pedestrian crossings, so cases have been studied inside Al-Haram Street that
express the different types of crossings, and observation and monitoring has
been relied on through field visits, photography and aerial maps. The results
indicated that one of the most important reasons for non-compliance with some
Pedestrians in the roads of their own lanes is the lack of infrastructure necessary
to provide safe points for dispersed crossing, lack of traffic culture, failure of the
designer to take into account the behavioral aspect of pedestrians, in addition to
the absence of deterrent laws for violators.

Abstract-Pedestrians are the basic nucleus that uses the road, but interest in them did not emerge as a major indicator in the planning and design processes, and the study gave high focus on pedestrian behavior and how they deal with their crossings as the most important equipment that provides a safe and comfortable environment for pedestrian traffic, and the efficiency of the crossings And its importance in preventing pedestrian traffic from interfering with vehicle traffic and the extent of its respect for the behavioral aspect of the planning process. Al-Haram Street suffers from traffic problems with regard to pedestrian crossings, so cases have been studied inside Al-Haram Street that express the different types of crossings, and observation and monitoring has been relied on through field visits, photography and aerial maps. The results indicated that one of the most important reasons for non-compliance with some Pedestrians in the roads of their own lanes is the lack of infrastructure necessary designer to take into account the behavioral aspect of pedestrians, in addition to the absence of deterrent laws for violators.

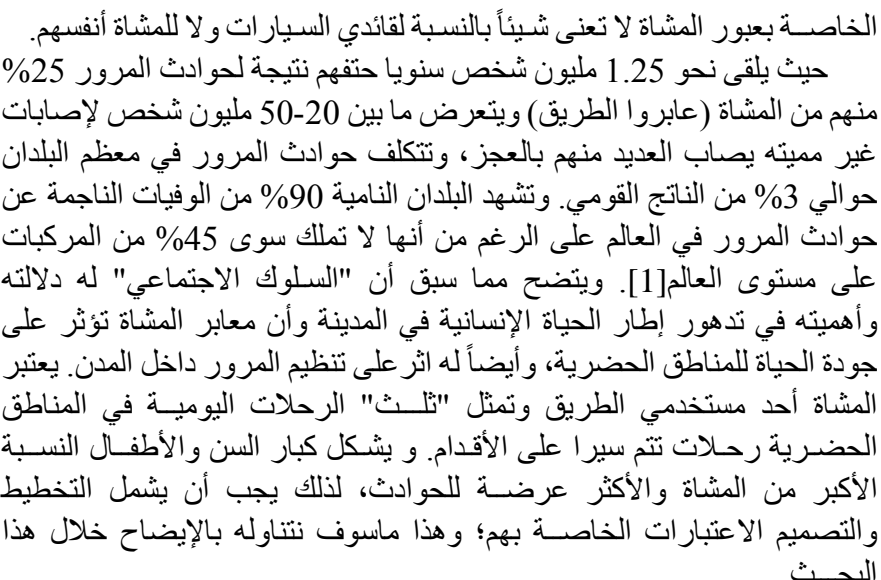

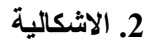

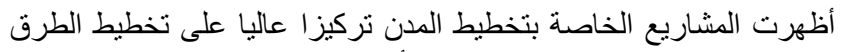
باعتبار ها ابرز مكونات البنية الحضرية الأساسية للمدينة التي تثبن التبع احتياجات

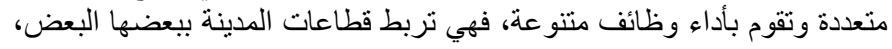

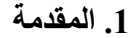

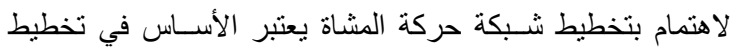

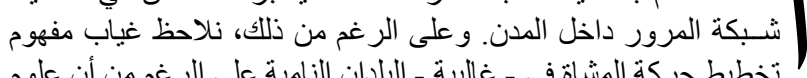

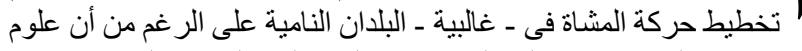

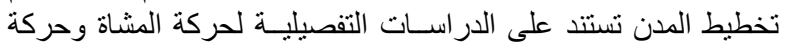

الآليات كأسـاس لتخطيط استعمالات الأراضي. وتحتوى المخطط الفــات الحديثة

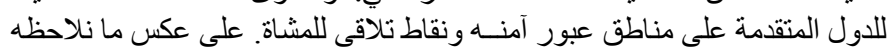

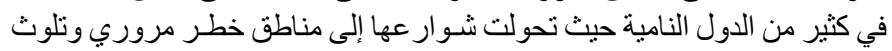

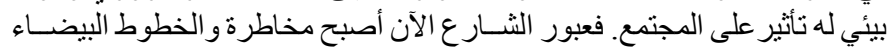

Received: (05 May, 2021) - Revised: (31 July, 2021) - Accepted: (01 August, 2021)

*Corresponding Author: Ahmed Mahmoud Nagi, Assistant Professor, Head Of Architectural Department, Elgazeera Higher Institute of Engineering and Technology in Mokattam. (e-mail: nagitos@hotmail.com).

Dalia Shalaby Eldamaty, Assistant Professor, Elgazeera Higher Institute of Engineering and Technology in Mokattam.(e-mail: nature_design2015@ yahoo.com). 
المعابيرالتصديمية لمعابر المشاة السطحية تفصل المعابر السطحية بين المشاة ومرور المركبات، لفترة وجيزة أثناء

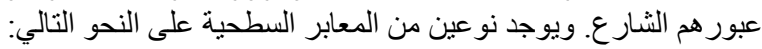

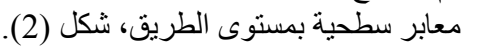

معابر سطحية بمستوى الرصيف (تكون في صورة مطب)، شكل شكل (3).

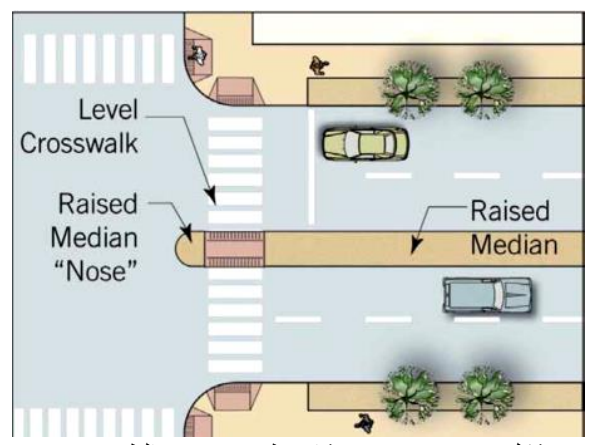

شكل (2) يوضح معبر مشاة سطحي بمستوى الطريق.]
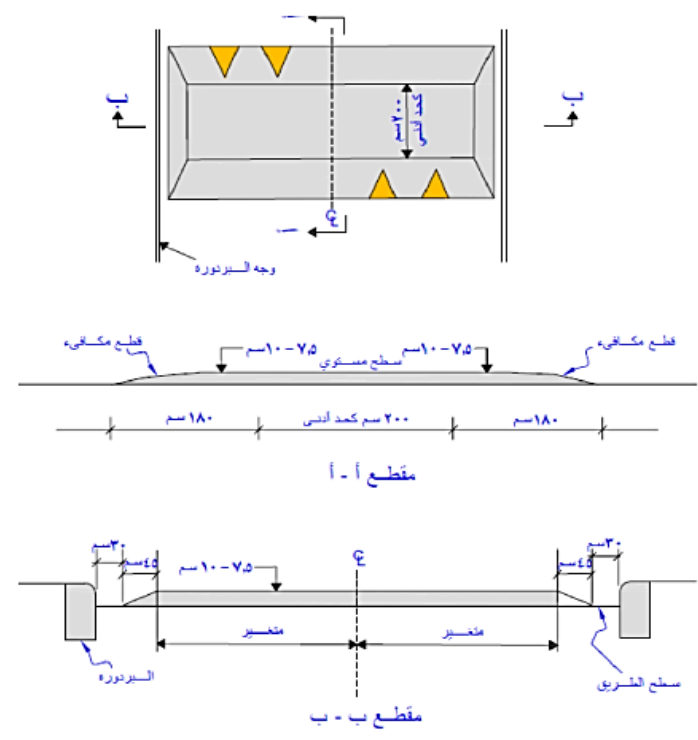

شكل (3) يوضح معبر مشاة سطحي بمستوى الرصيف.[5

يراعى فيها المعابير التصمبية التالية:

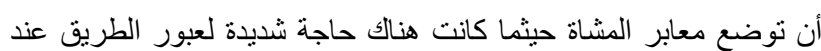

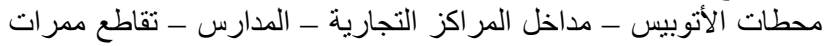

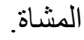

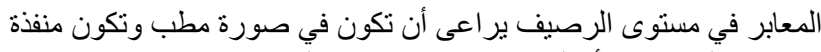

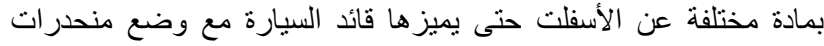
للسيار ات بنسبة 1:12، شكل (4) السفي

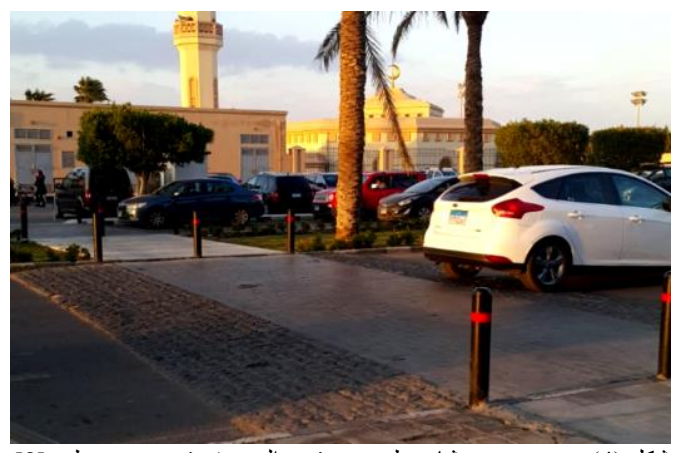

شكل (4) يوضح معبر مشاة سطحي بمستوى الرصيف في صورة مطب.[2]
وبر غم هذا التركيز العالي على توزيع اماكن ومساحات الطرق بأنماطها المتنو عة، ألمات

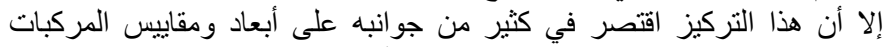

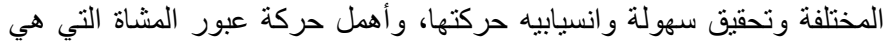

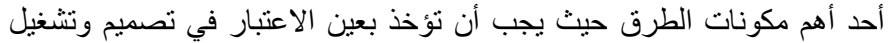

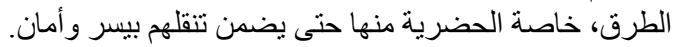

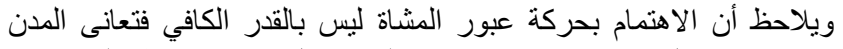

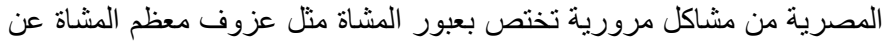

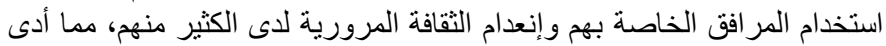

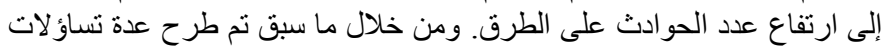

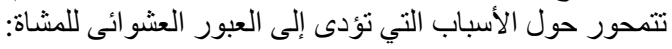

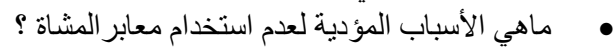

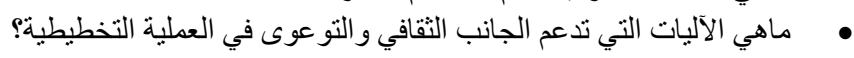

\section{3. أهداف البحث}

توفير معابر مشاة تتسم بالر احة و الأمان لمستخدميها.

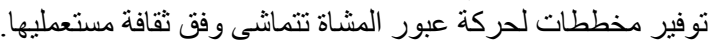

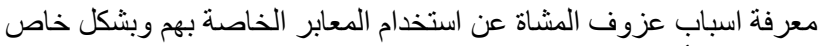
الكباري و الأنفاق وحثُهم على استخدامها و العمل على المعابر الة الة معوقات استخدام

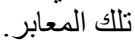
رفع جودة الحياة بالمناطق الحضرية عن طريق معابر المشاة الآمنة كأحد الأدوات لذعب دة اللك.

\section{4. المنهجية البحثية}

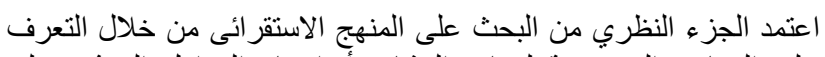

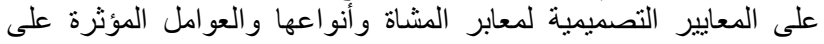
تخطيطها وتصميمها.

كما اعتمد الجزء التطبيقي من البحث البه على المنهج التحليلى في تحليل

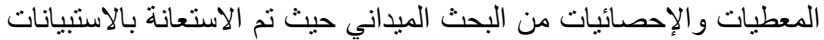

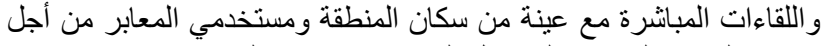

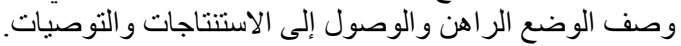

\section{5. المعاييرالتصميمية لمعابر المشاة}

مفهوم معابر المشاة

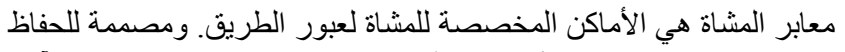

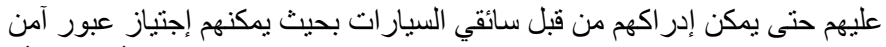

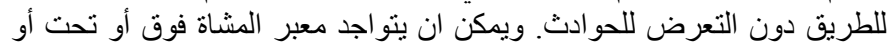

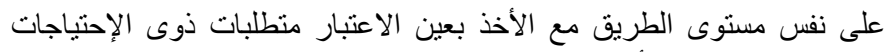

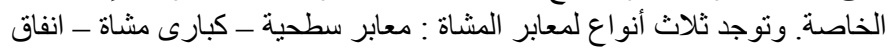

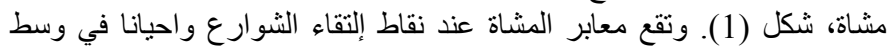
الثوار ع حيث يتوقع حركة كبيرة للمشاة.

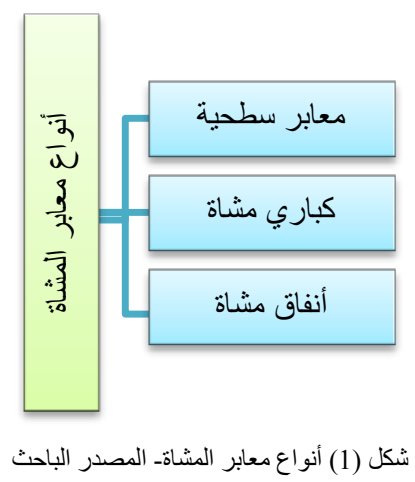


منحدر البردورة في الأرصفة عند التقاطعات يكون بعرض لا يقل عن $1.25 \quad$ التالية:

يجب أن تكون مضاءة بشكل كافي وو اضحة للمشاة. [5]

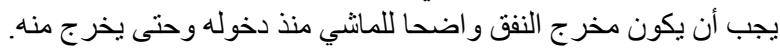

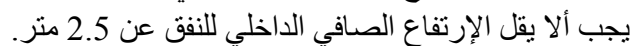

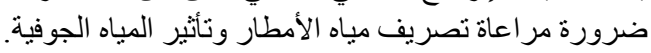
ير اعى تأمين تهوية كافية لنفق المشاة. ير اعي تلبية منطلبات ذوى الإحتياجات الخاصة حتى لئى يناح لهم استخدام نفق يفضل استعمال أنفاق عبور المشاة في الاماكن التي تكثر فيها حركة

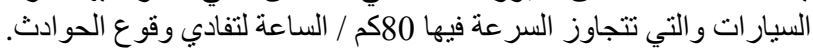

\section{العوامل المؤثرة على تخطبط وتصميم معابر المشاة}

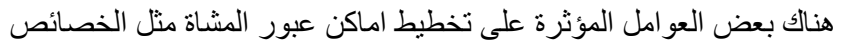

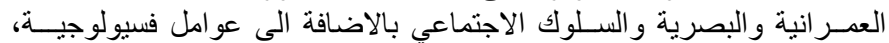
شكل (6)، كما يلي: ولئ ولئ

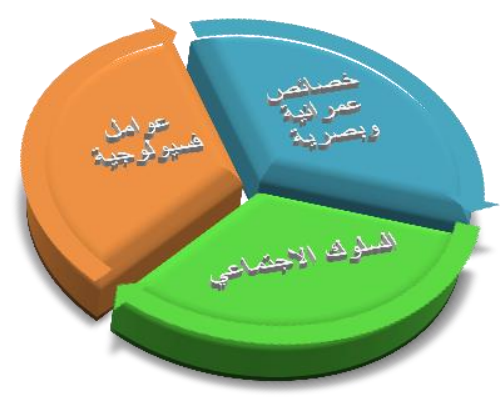

شكل (6) يوضح العوامل المؤثرة على تخطيط وتصميم معابر المشاة - المصدر الباحث.

区 وتثثمل حالات المباني وارتفاعاتها والكية والكثافة البنائيـة وتوزيع استعمالات

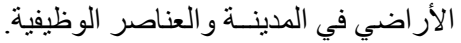

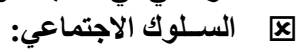

هو محصلة البيئة الحضاعية الحضارية للمدينة التي يحيا فيها الإنسـان، بشقيها

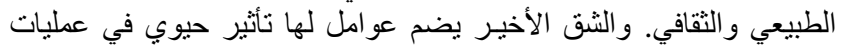

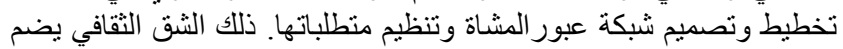

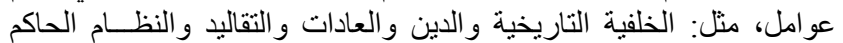

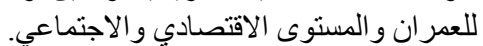

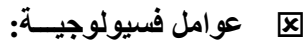
تتضمن سرعة الإنسان ومسـافة السـير والقدرة على تحملها في البيــــات العمــر انيــة المختلفــة الإنسان.

كفاءة معابر المشاة تعتمد كفاءة معابر المشاة على كثافة المسار وظروف المثاة السير ، كما يلي: كثافة المسار:

تعرف كثافة المسار بحساب أعداد الأشخاص المترجلين و المتو اجدين في لحظة واحدة على مساحة منر مربع واحد.

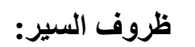

تتنوع ظروف السير ويختلف مكان السير من مدينة إلى أخرى ومن منطقة

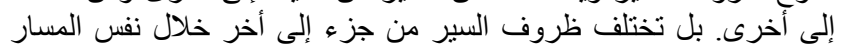
ووقت السير من يوم إلى أخر ومن ساعة إلى أخرى.

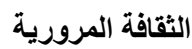

الثقافة المرورية عبارة عن محصلة سلوك الانسان. فالسائق الذي يحافظ على لى

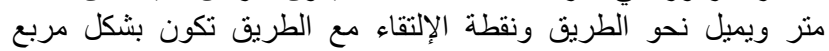

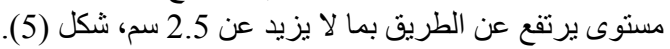

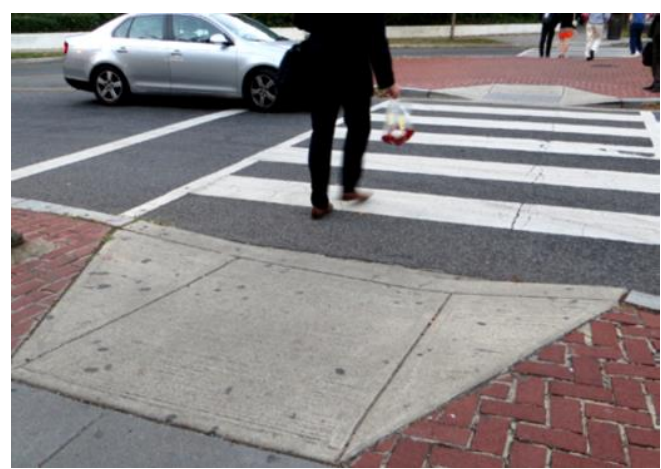

شكل (5) يوضح منحدر البردورة لمعبر مشاة سطحي بمستوى الطريق.[2]

يجب أن يعطي خط التوقف للسيار ات الإحساس بالأمان للمشاة وعدم الخوف

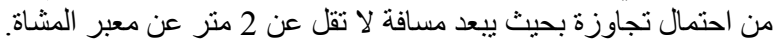

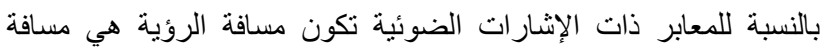

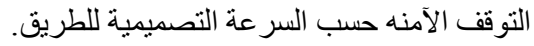

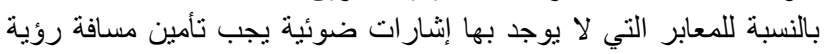
كافية لكي يرى المشاة السيار ات الفئر القادمة.

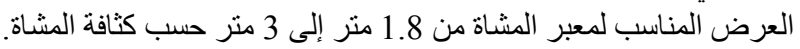

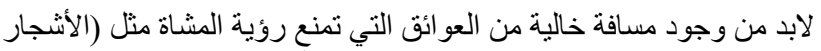

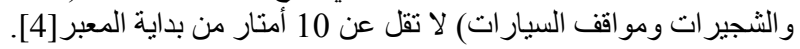

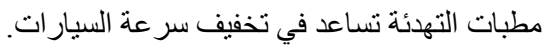

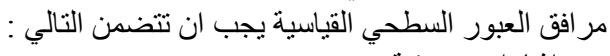
O مر إثار ات ضورئية. O بردورة مقطو عة عند الأرصفة بضفتي الشار ع و الجزيرة الوسطى.

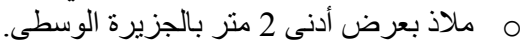

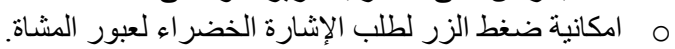

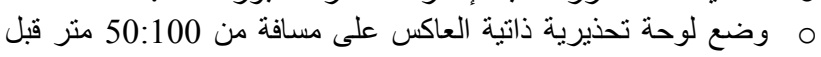

[5]. المعبر

o يمكن طلاء المعبر بلون عاكس أو استخدام شريط عاكس خاص بلاص بالأسفلت لتحسين رؤية المعبر ليلا.

$$
\text { الدعابير التصديمية لكباري المشاة }
$$

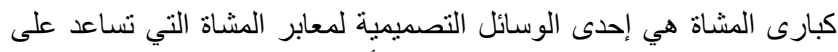

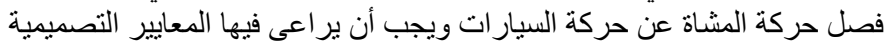

التالية:

• • •

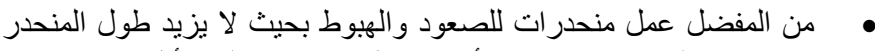

عن 9 متر يليه مسافة إستر احة أفقية بطول 1.5 متر على الميل الأقل.

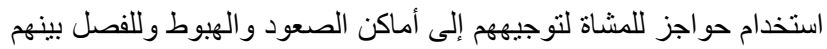
وبين حركة السيار ات. الات. يجب ألا يقل الخلوص الر أسي الصافي عن 5.5 منر من سطح الأسفلت إلى

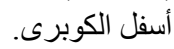
ير اعي تلبية منطلبات ذوى الإحتياجات الخاصة حتى يتاح لهم استخدام كوبرى المشاة. يفضل استعمال كباري عبور المشاة في الاماكن التي تكثر فيها حركة

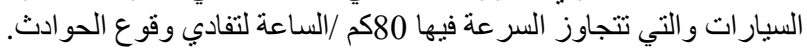

\section{المعابيرالتصمبية لأنفاق المشاة}

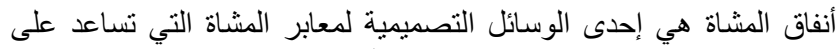

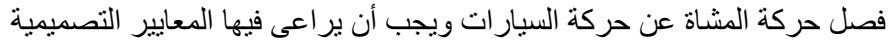


تجربية مدبيتة نبيودلهي بالهند:

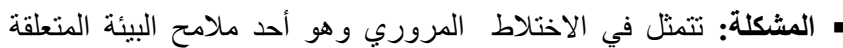

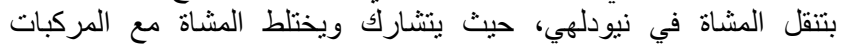

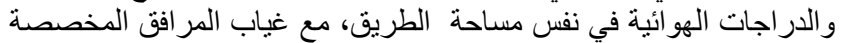

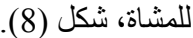

الإجراءات: قامت حكومة مدينة نيودلهي بوضع خطة لتحة لتحسين تصميم الطرق

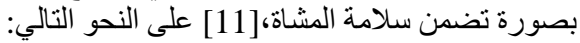

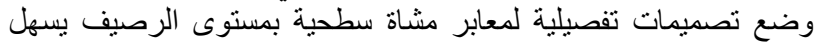

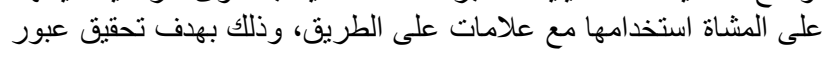

استخدام إثار ات مرور ضوئية أوتوماتيكية للتحكم في حركة المرور.

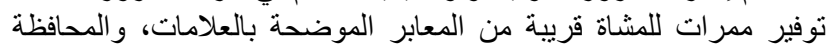

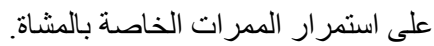

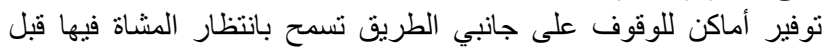
عبور هم الطريق وتستو عب الباعة الجائلين.

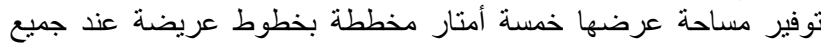
التقاطعات لتكون معابر للمشاة ويسبقها خط لوقوف السيارات يبعد ثلاثة

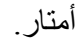
عمل شر ائح ارتجاجية (خطوط التنبيه الأرضية) لتقليل سرعة الحافلات .

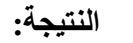
- انخفاض العبور العشو ائي للطرق و انخفاض الحوادث.

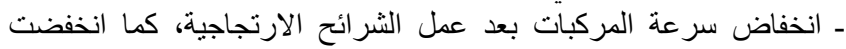

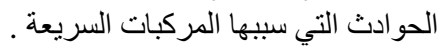

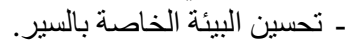

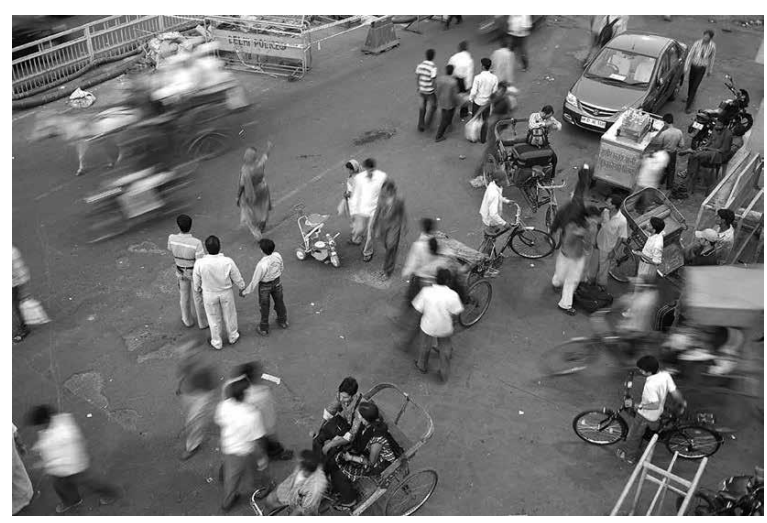

شكل (8) يوضح الاختلاط المروري في مدينة نيودلهي.[3]

$$
\text { تجرية مدينة /بوظبي بالإمارات: }
$$

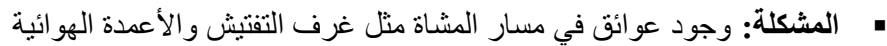

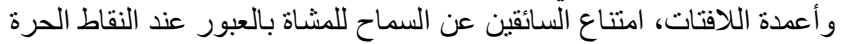
للإنعطاف إلى اليمين، إصطفاف المركبات المبات على المعابر (المطبات) السطحية المبات

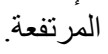

الإجراعات: قام مجلس التخطيط الحضري بأبو ظبي بإعداد دليل تصميم

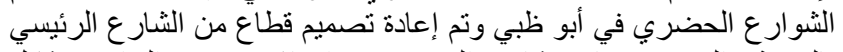

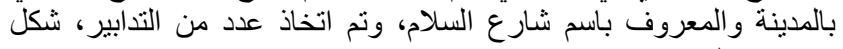
(9)، كما يلينة ولمعروين

إنفاذ قو انين المرور لضمان احترام سائقي المركبات لحقوق المشاة في عبور الطريق.

تنفيذ بر امج للتقيف و التوعية بالقو انين المرورية المتعلقة بحماية المشاة. تقييم التدابير المتبعة بغرض التحسين والتطوير وتلافي التبرونة الأخطاء.

• النتيجة: تحسنت مر افق المشاة في الثار ع بعد إعادة تصميمه، كما يلي:

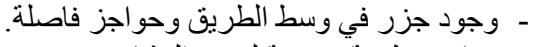
- - معابر سطحية مرتفعة لعبور المشاة.

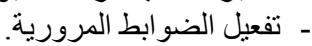

نظام المرور ويتقيد به ويسير وفق تعليماته يعنى أن لديه ثقافة مرورية تضبط

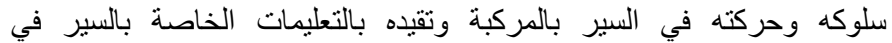

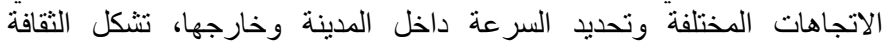

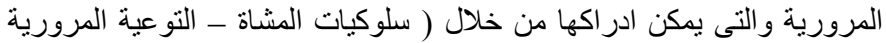

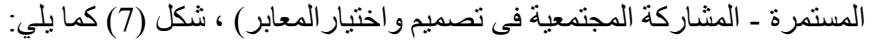

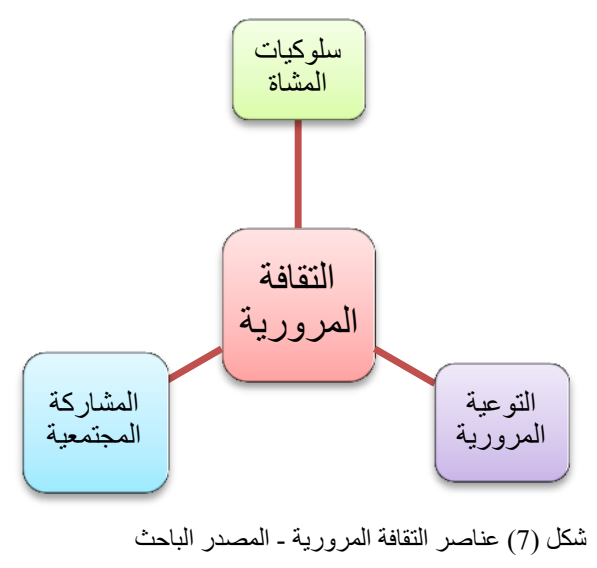

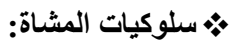

هناك عدة خطوات يمكن إتباعها لحماية المشاة على الطرق ستسهم بفعالية و على نحو مستدام في جعل العبور آمنا، كما يلي: سن التشريعات الخاصة بتعاطي العقاقير المخدرة واستخدام اجهزة المحمول

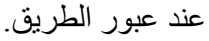
• شر الوعي بين المشاة حول أهمية ارتداء الملابس التي تحمل علامات عاكسة للضوءء. حث المشاة على الالتزام بالإشار ات المرورية وقو انين المرور بصورة عامة وذللك لنزكية ثقافة السلامة.

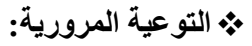
ترتبط التوعية المرورية بدرجة وعي المو اطن في الجو انب التالية:

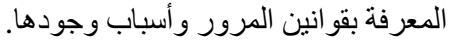

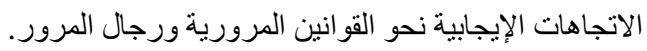
• السلوكيات الإيجابية في القيادة.

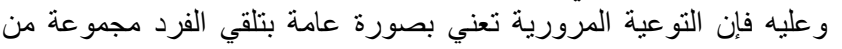

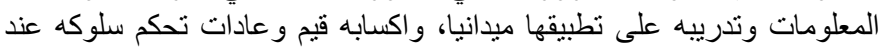
التعامل مع الطريق سائقا أو عابر ا.

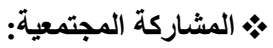
هي تتظيم جهود أفراد المجتمع للعمل مع الأجهزة الرسمية وغير الرسمية

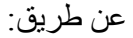
• استشارة الأهالي و المجمو عات المستهدفة و عمل مقابلات ومـؤتمر ات عامة.

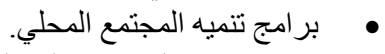
• الاستبيانات و الدر اسات المختلفة التى تستهدف معرفة رأي المجتمع المدني.

\section{6. التجارب العالمية لمعابر المشاة}

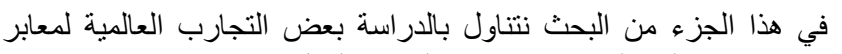

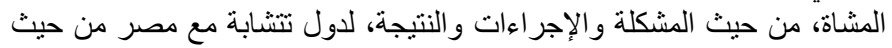
طبيعة المشكلات و الظروف الاجتماعية أو الثقافية أو الإقتصادية، كما يلية لإنية 
• النتيجة: لم يستخدم الكوبري سوى ثلث المشاة العابرون للطريق ومعظمهح

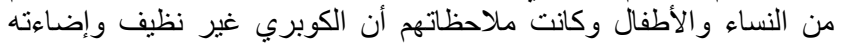

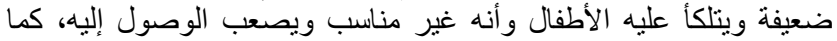

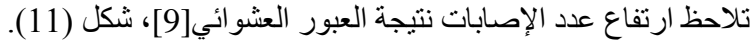

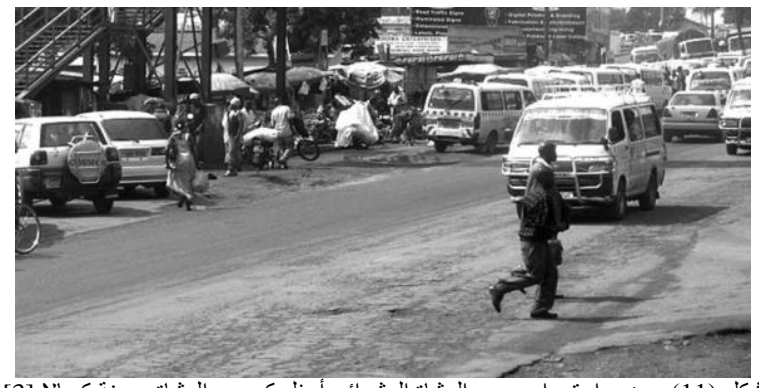

[3كل (11) يوضح استمر ار عبور المشاة العشو ائي أسفل كوبري الشاة بدينة كببالا.

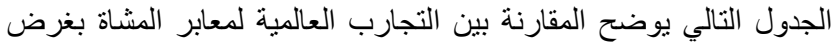

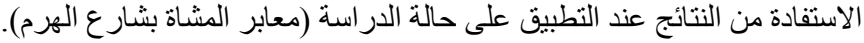

\begin{tabular}{|c|c|c|c|c|}
\hline كمبالا (أوغندة) & زايتانج (الصين) & (ألاماراتي) & نيودلهي (الهند) & \\
\hline ـالعبابور مر افقت ائي & 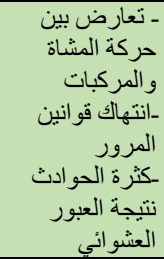 & 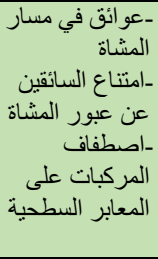 & العباب مر العنق & المشكلة \\
\hline للمشاء كوبري & بغرض تنفيذ تدابير & 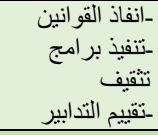 & ـانسية مشارية مرور & الاجراءات \\
\hline 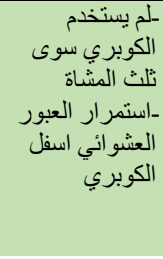 & 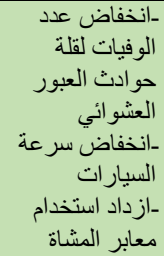 & 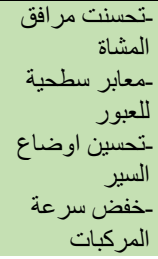 & 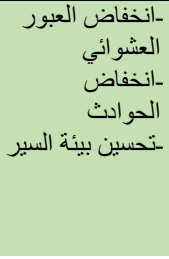 & النتيجة \\
\hline
\end{tabular}

7. دراسة حالة معابر المشاة بشارع الهرم

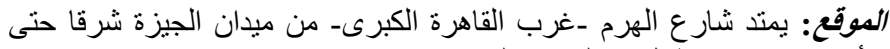

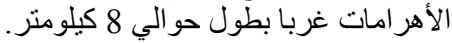

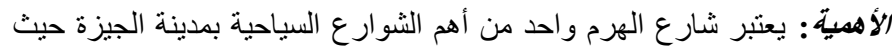

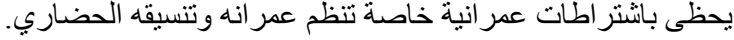

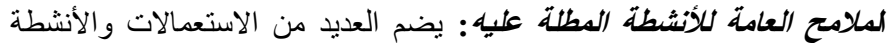

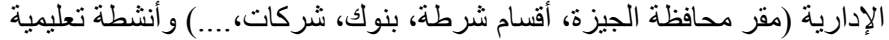

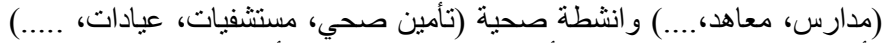

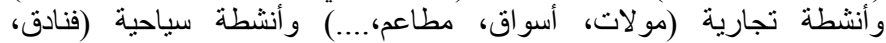

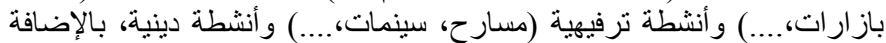

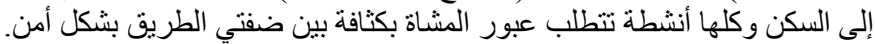

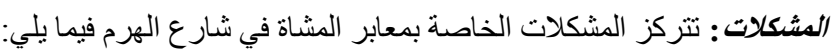

$$
\begin{aligned}
& \text { • غياب مر افق العبور السطحي. } \\
& \text { • احجام المشاة عن استخدام كباري وأعبار أنفاق المشاة. } \\
& \text { • العبور العشو ائي. } \\
& \text { • انتهاك قو انيين المرور . } \\
& \text { • كثرة الحو ادث نتيجة العبور العشو ائي. }
\end{aligned}
$$

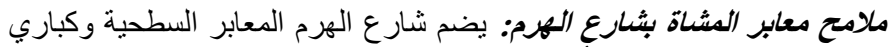
المشاة (كوبري المطبعة) وأنفاق المشاة (نفق الطالبية ونفق اللبيني)، شكل (12)، المعاير البطة
- ـ تحسين أوضاع السير بشكل عام. - خفض سرعة المركبات بمقدار من 4-10 كم/مامداعة نتيجة تضيق الحار ات

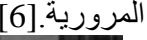

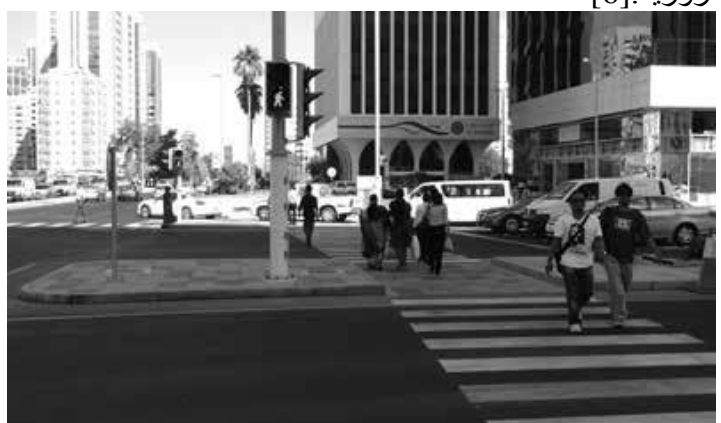

شكل (9) يوضح أحد معابر المشاة السطحية والمزود باثارات ضوئية بمدينة أبو ظبي.]3]

تجرية مدبيتة زايتانج بالصبن:

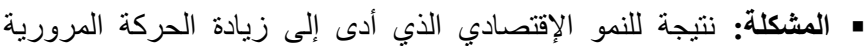

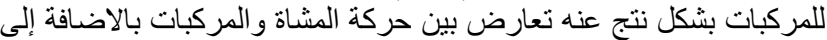

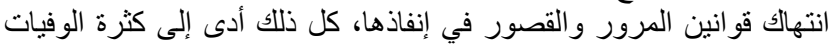
والحوادث نتيجة العبور العشو ائي للمشناة.

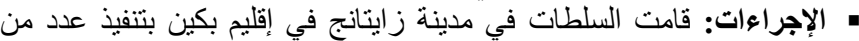

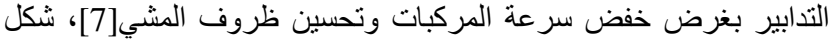

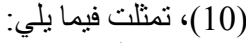
. معل مطبات إنسيابية. • أرصفة المشاة البارزة و المرتفعة وكذلك التقاطعات البارزة.

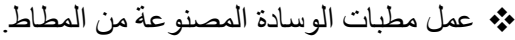
• ثنفيذ عدد من التقاطعات الدائرية (الدورانات) والماطن المنحنيات الأفقية المعاكسة (الطرق المنموجة). • ثضييق الحارات المرورية عند التقاطعات عن طريق امتدادات الأرصفة. • النتيجة: انخفاض عدد الوفيات والإصابات نتيجة حوادث العبور العشوائي

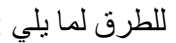

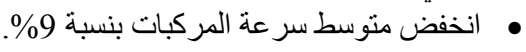
• • • • •

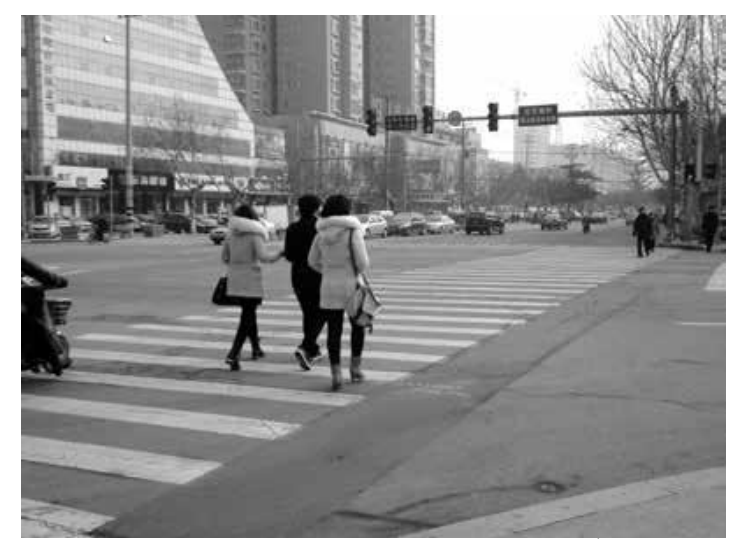

شكل (10) يوضح أحد معابر المشاة السطحية والمزود باثار ات ضوئية بمدينة زيتانج.[3]

تجرية مدينة كمبالا بأوغندة:

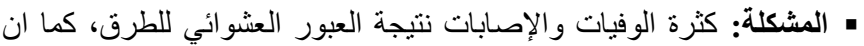

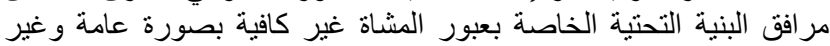

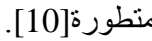

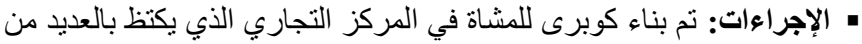

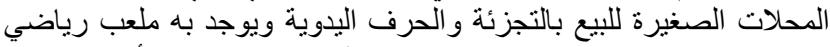

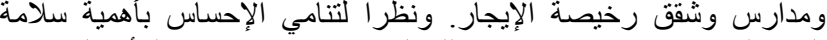
المشاة لحدوث عدة تصادمات في ذللك الموقع تسببت في إثارة الر أبي العام. 


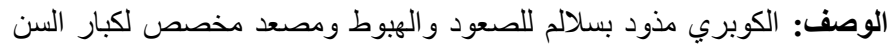

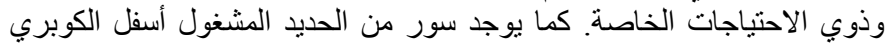
بالجزيرة الوسطى لمنع عبور المشاة سطحيا واجبار هم على استخدام الكوبري.

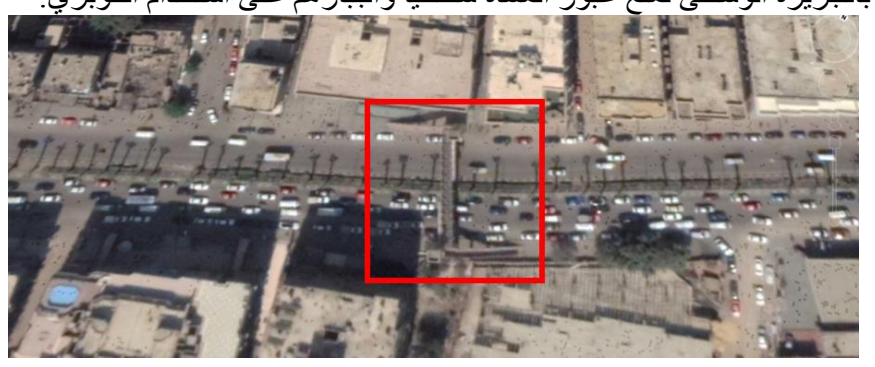

شكل (14) يوضح موقع كوبري مشاة المطبعة بشارع الهرم.[8]

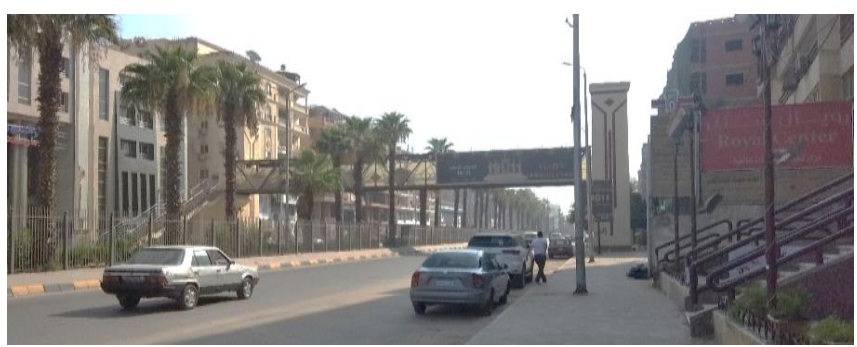

شكل (15) صورة توضح كوبري مشاة المطبعة بشارع الهرم - المصدر الباحث

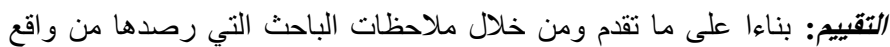
الزيارات الميدانية والاستبيانات و المقابلات الثخصية مع مستخدمي كوبري مشاة

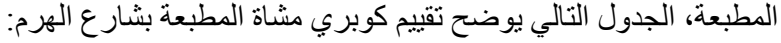

\begin{tabular}{|c|c|c|}
\hline ملاحظات & التقييم & المعاييز \\
\hline 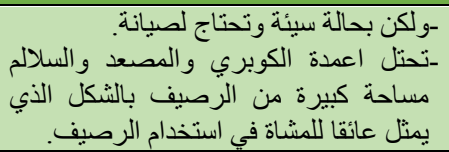 & متوفرة & الكوبرية \\
\hline - شيوجد مصعد مخصص وكبار السن ولكن الاحتباجات معطل، & متوفرة & الاحتبياجات \\
\hline 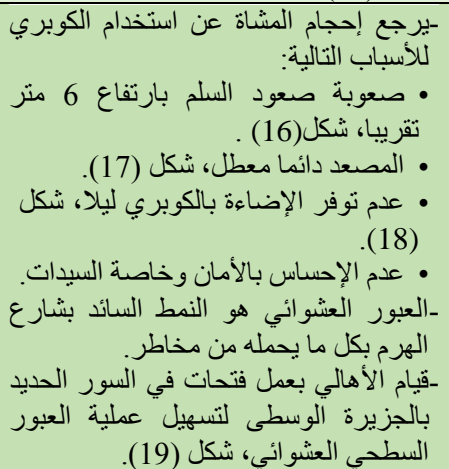 & 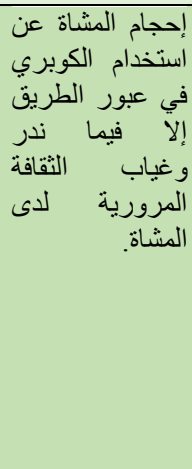 & سلوكبات المشاة \\
\hline 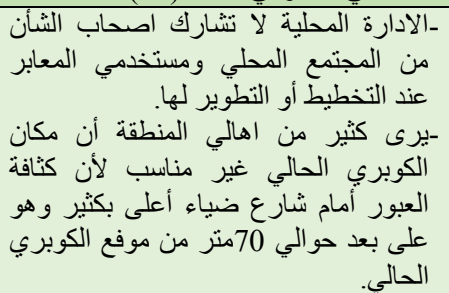 & غير موجودة & الشأناركة أصحاب \\
\hline 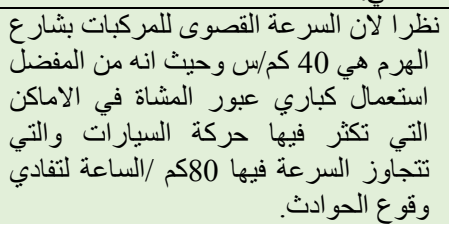 & غير منوفرة & الضرورة الفنية \\
\hline
\end{tabular}

مع العلم أن السر عة القصوى للمركبات بشارع الهرم هي 40 كم/ساعة، وسوف يتناو لها الباحث بالو الوصف و التحليل و التقييم، على النحو التالّي:

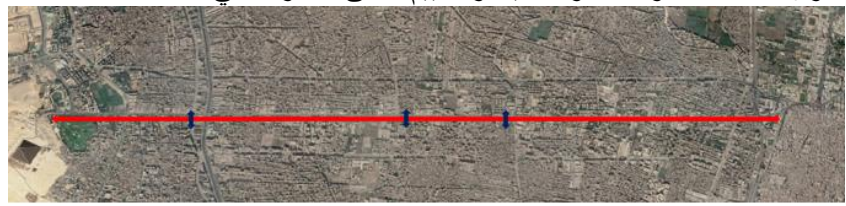

شكل (12) يوضح منطقة الدر اسة (شارع الهرم) وما يضمه من معابر سطحية وكباري و أنفاق [8] مشاة

\section{معابر المشاة السطحية بشارع الهرم:}

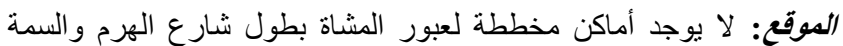

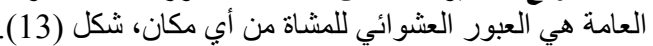

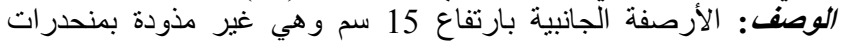

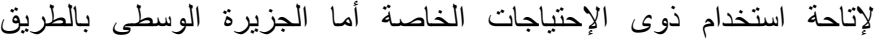

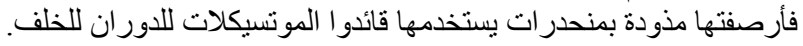

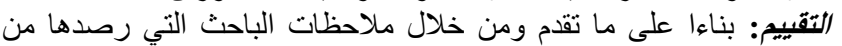

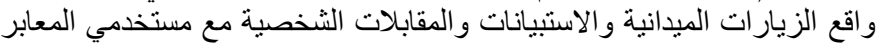

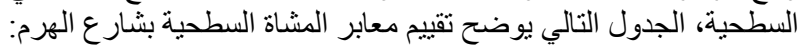

\begin{tabular}{|c|c|c|}
\hline ملاحظات & التقييم & المعاييز \\
\hline 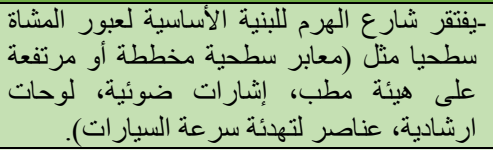 & غير متوفرة & اللمعابر السبة التحتبية \\
\hline 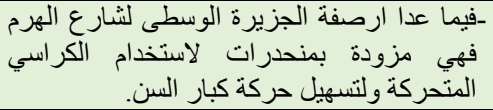 & غير متوفرة & الاحتبياجات ات ذوى \\
\hline 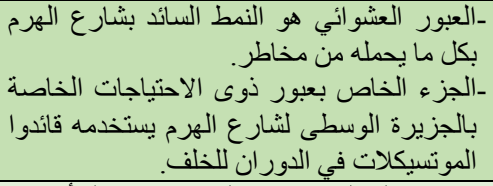 & المياب المشاة ورية لدائدية & المشاة وكبات \\
\hline 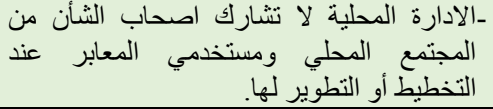 & غير موجودة & مشاركة \\
\hline 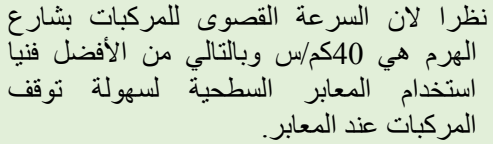 & متوفرة & الفنية الضروة \\
\hline
\end{tabular}

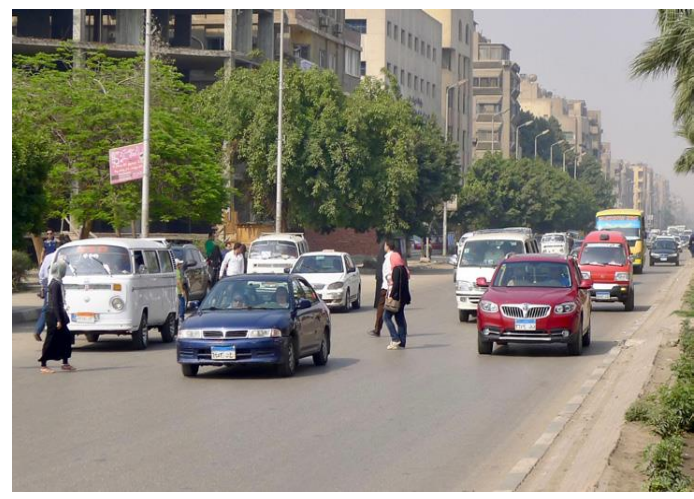

شكل (13) صورة توضح العبور العشو ائي للمشاة بشار ع الهرم.[2]

كوبيري مشاة المطبعة بشارع الههرم:

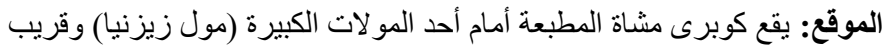

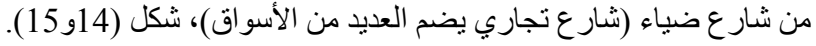



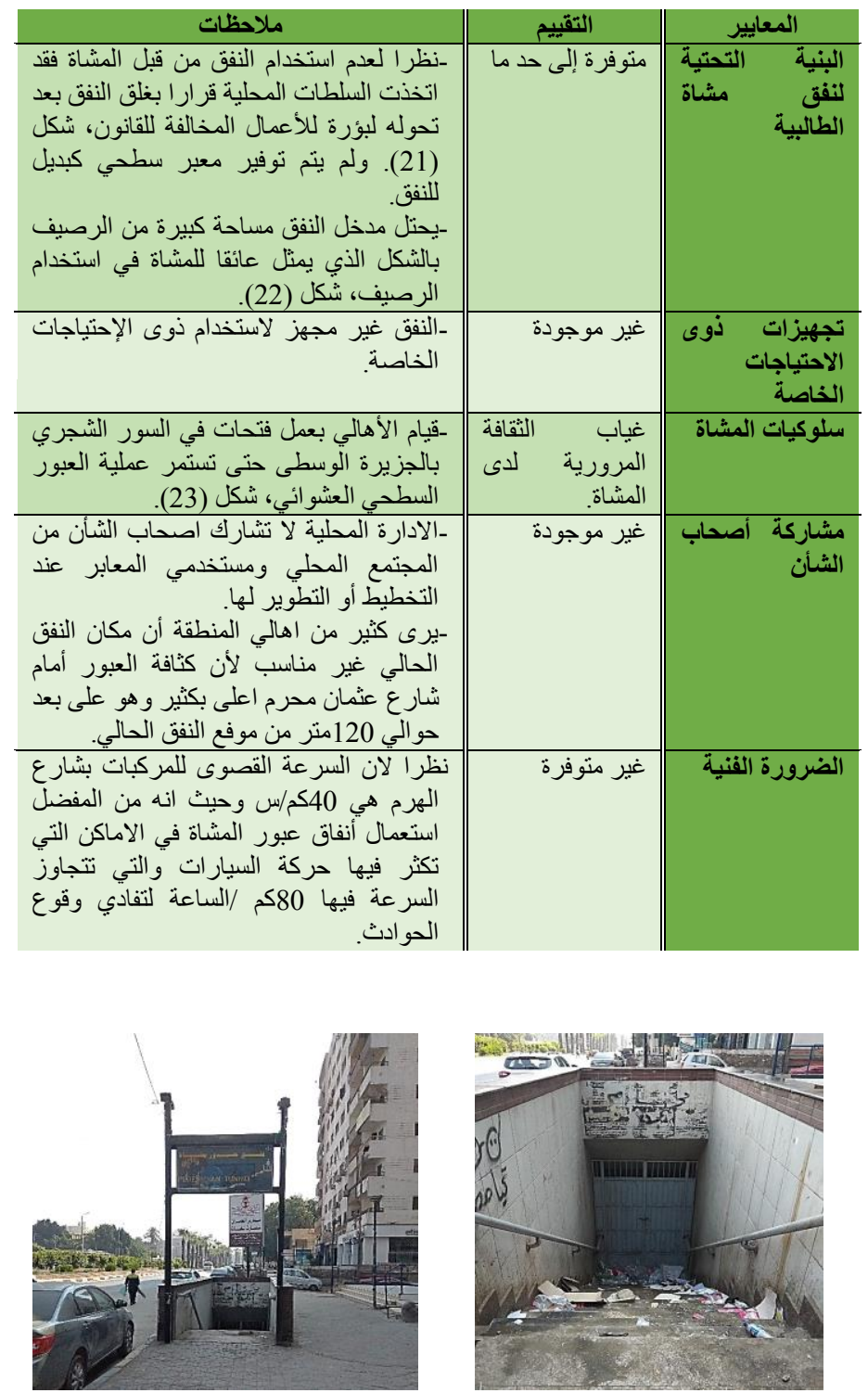

شكل (22) صورة توضح مدخل نفق المشاه بالطالية - المصدر الباحث

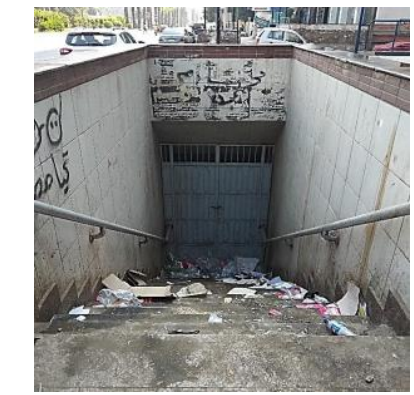

شكل (21) صورة توضح أن النفق مغلق كنتيجه لعدم استخدامه فاصبح بؤرة للأعمال المخالفة النغ للقانون - المصدر الباحث

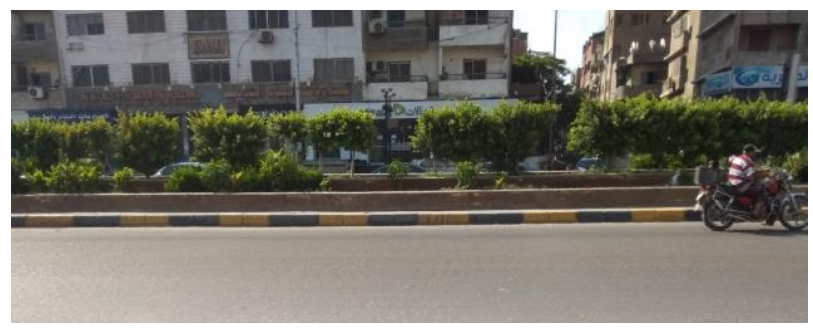

شكل (23) صورة توضح السور الثجري لمنع عبور المشاه السطحي و الذي تم عمل فتحات به لعبور

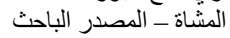

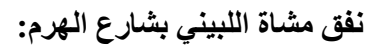

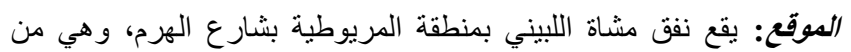

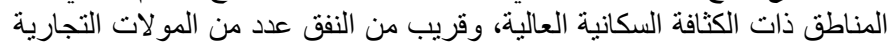
ومو اقف ميكروباص، شكل (24).

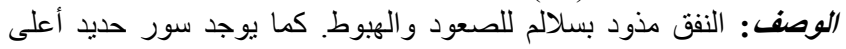
النفق بالجزيرة الوسطى للنع عبور المشاة سطحيا واجبار هم على استخدام النفق.
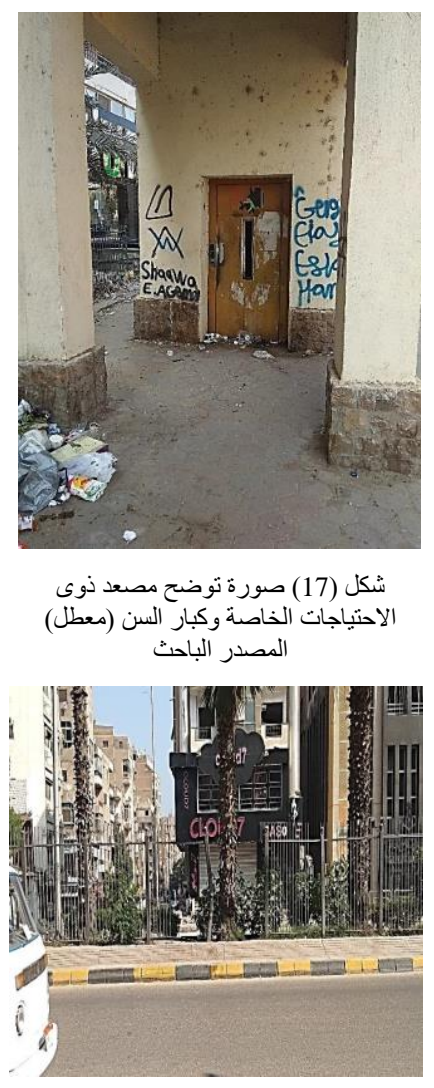

شكل (19) صورة توضح السور الحديد

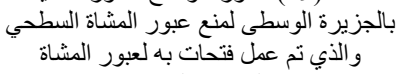

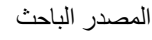

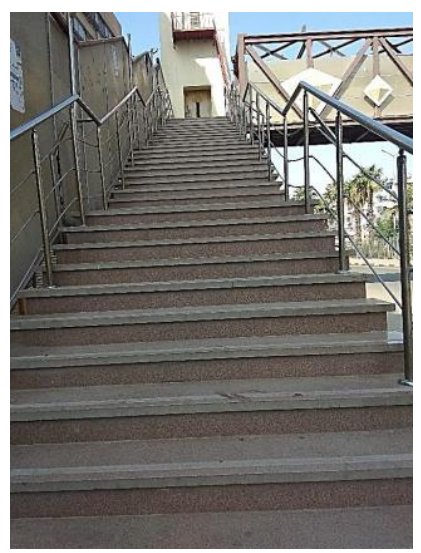

شكل (16) صورة توضح الدرج المؤدي ل اللكوبري بارتفاع 6 أمتار تقريبا المصدر الباحث ألمثار

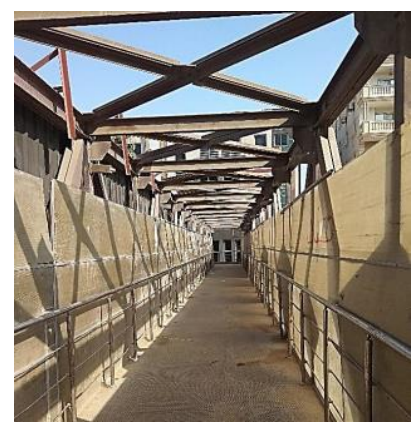

شكل (18) صورة توضح الجسم المعدني للكوبري وأسوار تأمين المشاة وتأمين الطريق الطيق

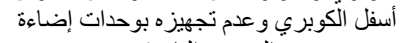

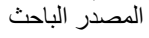

نفق مشاة الطالبية بشارع الهرم:

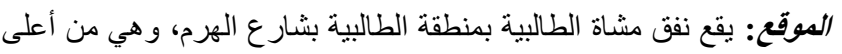

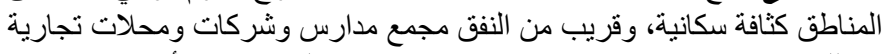

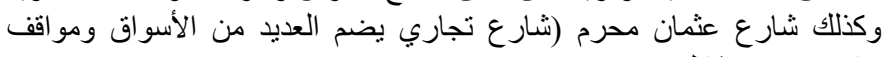
ميكروباص)، شنكل (20). (20)

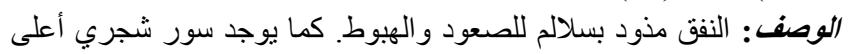
النفق بالجزيرة الوسطى لمنع عبور المشاة سطحيا واجبار هم على استخدام النفق.

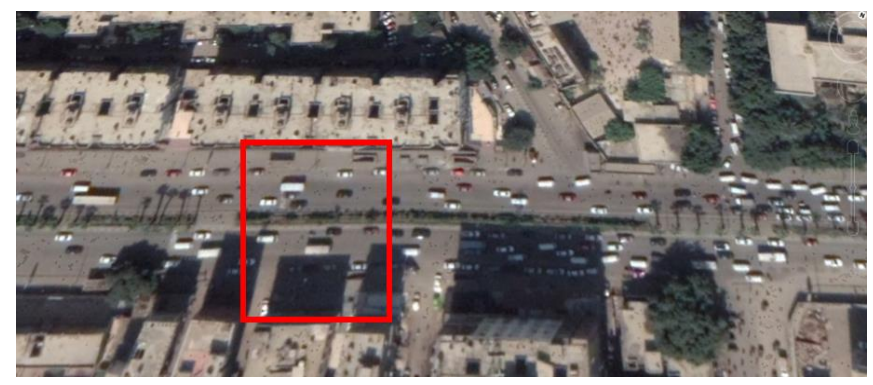

شكل (20) يوضح موقع نفق مشاه الطالبية بشارع الهرم.[8]

التقييم: بناءا على ما تقدم ومن خلال ملاحظات الباحث التي رصدها من

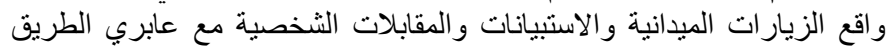

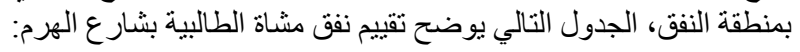




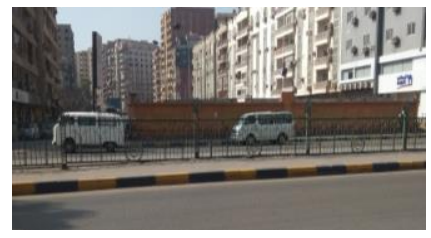

شكل (28) صورة توضح السور الحديد لمنع

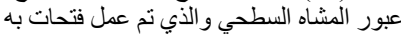
لعبور المشاة - المصدر الباحث تُ لمث

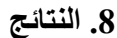

للانقافة المرورية والوعي باجر اءات الأمن والسلامة دور هام في استخدام

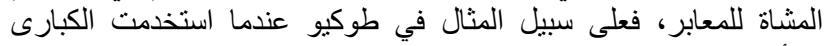

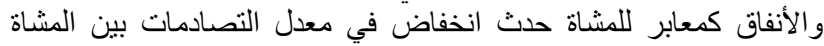

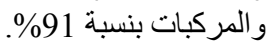

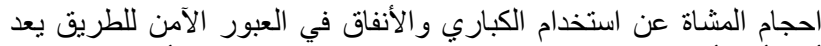

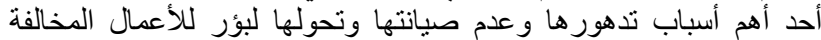
اللقانون.

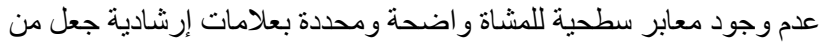

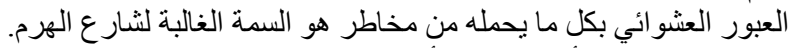

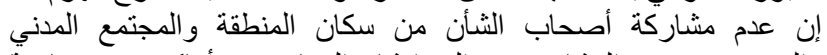

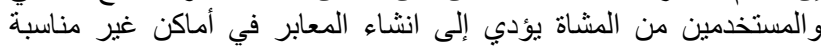

لمستخدميها.

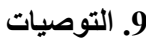

توصيات تتعلق بتحسين الوضع الحالي لمعابر المشاة:

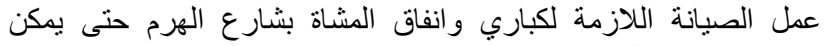

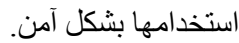
إعادة تأهيل نفقي المشاة بالطالبية و اللبيني بما يسمح باتاحة استخدامهما لذوي الاحتياجات الخاصة.

تخطبط أماكن العبور السطحي وبشكل خاص المام المام المدارس والأسواق التجارية بمشاركة أصحاب الثأن. نشر الوعي بالثقافة المرورية وأهمية العبور الآمن للحد من حوادث عبور الطريق.

توصيات تتعلق بالاعتبارات التصميمية التي يجب على متخذى القرار دراستها عند إنشاء المعابر في المستقبل:

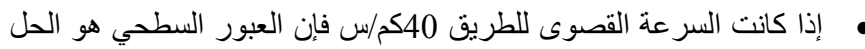

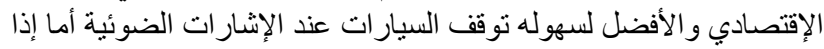

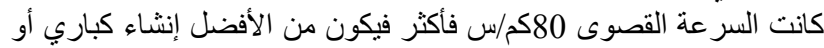
أنفاق لعبور المشاة.

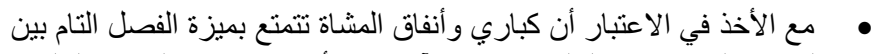

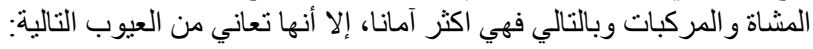

• • زيادة وقت التنقل بشكل لا يشجع المشاة على استخدامها.

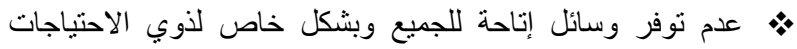

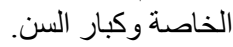

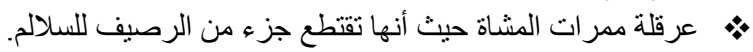

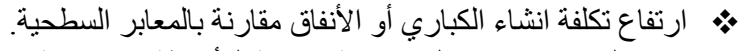

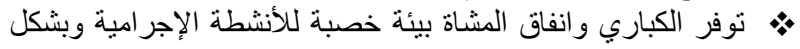
خاص ليلا. • ز زيادة نسبة الحوادث نتيجة زيادة سرعة السيارات في الأماكن المتوفر بها كباري أو أنفاق للمشاة.

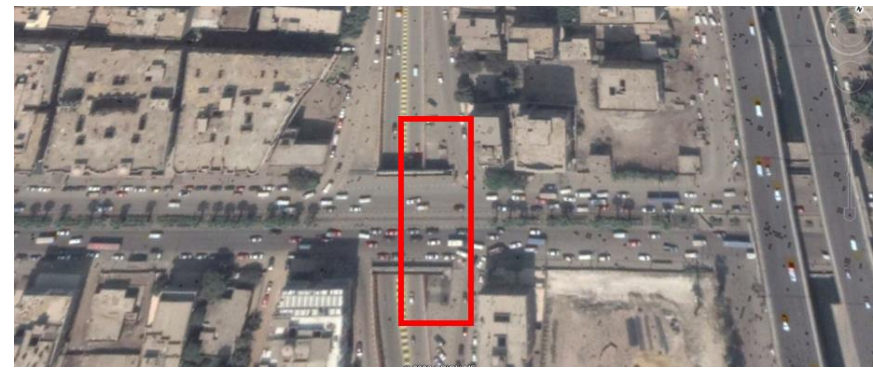

شكل (24) يوضح موقع نفق مشاه اللبيني بشارع الهرم.[8]

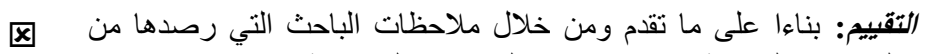

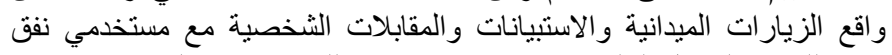

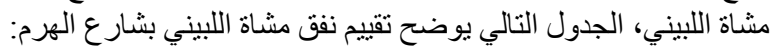

\begin{tabular}{|c|c|c|}
\hline ملاحظات & التقييم & المعايير \\
\hline ليعانون هذا النفق بؤرة للأعمال المخالفة & ما منوفرة إلى حد & النفلية \\
\hline ـالخاصقة غير مجزز لاستخدام ذوى الإحتياجات & غير موجودة & الإحتياجات \\
\hline 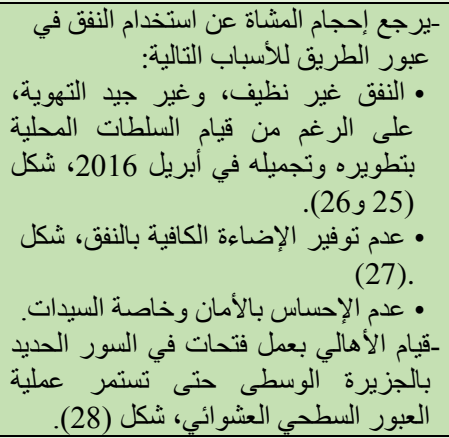 & الميرورية الدياب. & سلوكيات المشاة \\
\hline 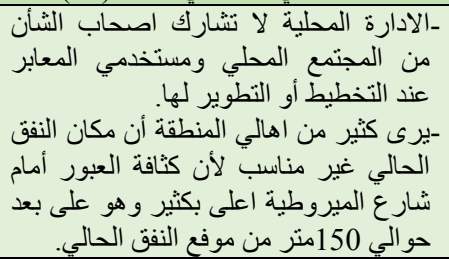 & غير موجودة & الشأن أشة أصحاب \\
\hline 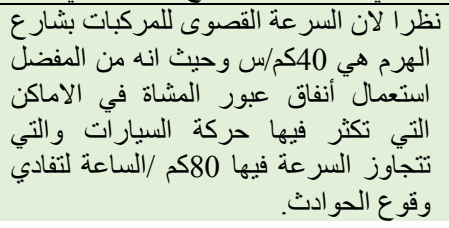 & غبر متوفرة & الضرورة الفنية \\
\hline
\end{tabular}

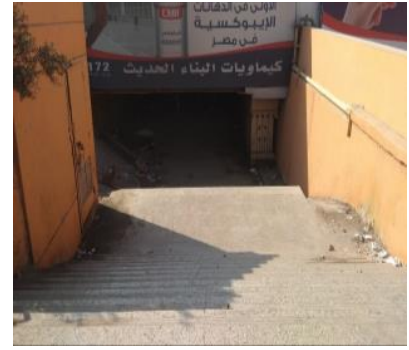

شكل (26) صورة توضح مدخل النفق من البن الجانب الآخر - المصدر الباحث مدخ

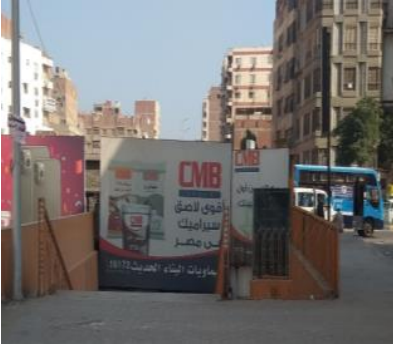

شكل (25) صورة توضح مدخل نفق المشاة

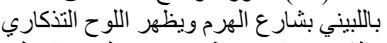
الذي يفيد انه تم تطويره وتجميله في ابريل التيل 2016 - المصدر الباحث 


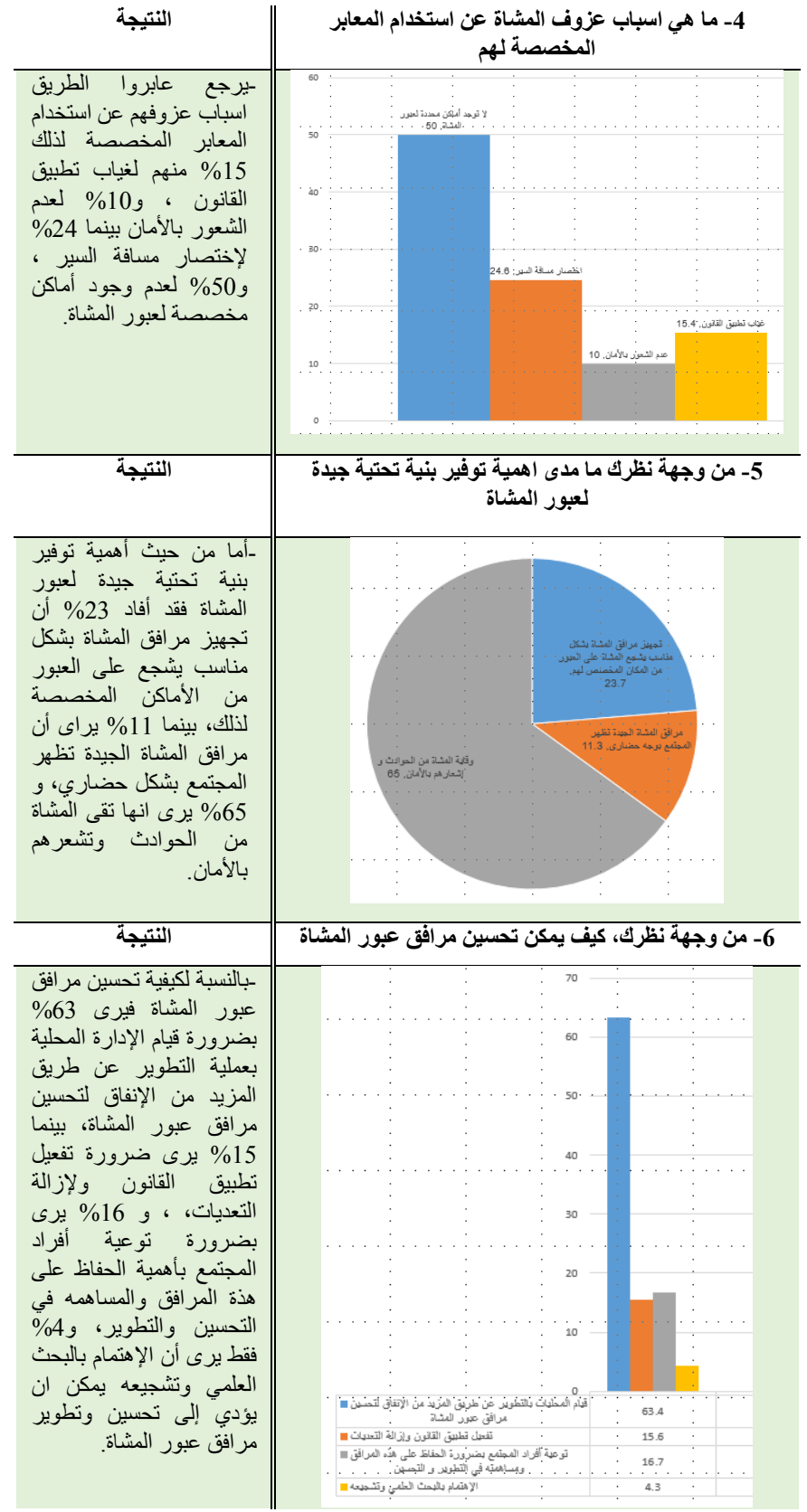

2

الأنماط العالمية التي تناولت معابر المشاة ضمن مبادئها:

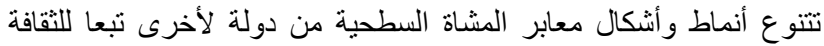

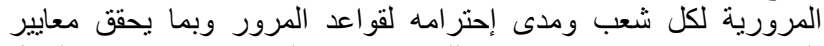

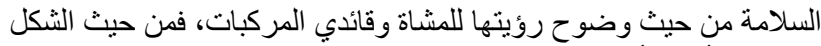

توجد عدة أنماط أثهر ها (Continental)، شكل (29) (29).

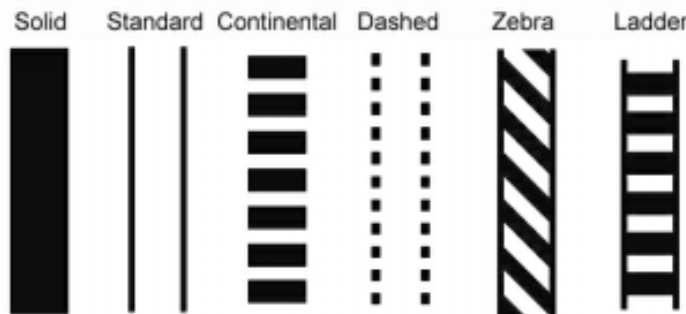

شكل (29) يوضح أنماط مختلفة لثنكل دهان معابر المشاة السطحية.[13]
• يجب أن تصمم الطرق مع مر اعاة مأمونيتها بالنسبة لجميع مستخدميها

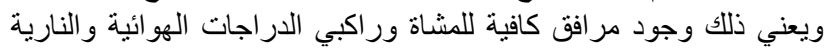

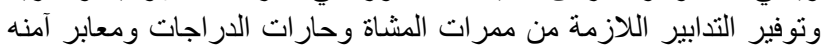

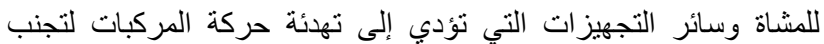

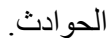
مشاركة أصحاب الثأن عنصر هام لوضع سياسات وبر امج ومشروعات يدعمها عموم الناس ويتقون بهاب.

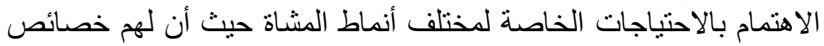

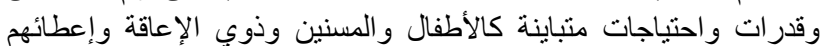

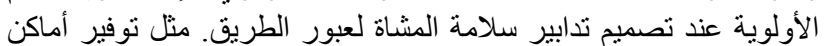

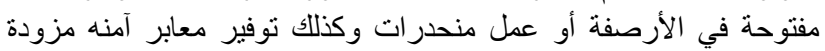

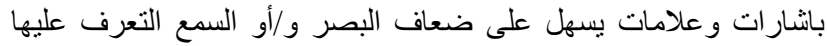

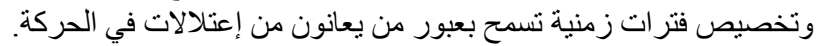

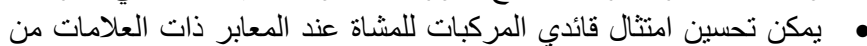
خلال إذكاء الوعي، و التثقيف، و إنفاذ القو انين.

ملحق 1

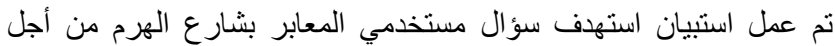

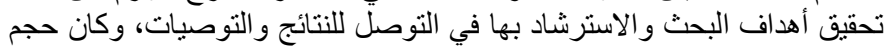
العينة الدر اسة 120 شخص، وكانت النت النتائج على النحو التالي:

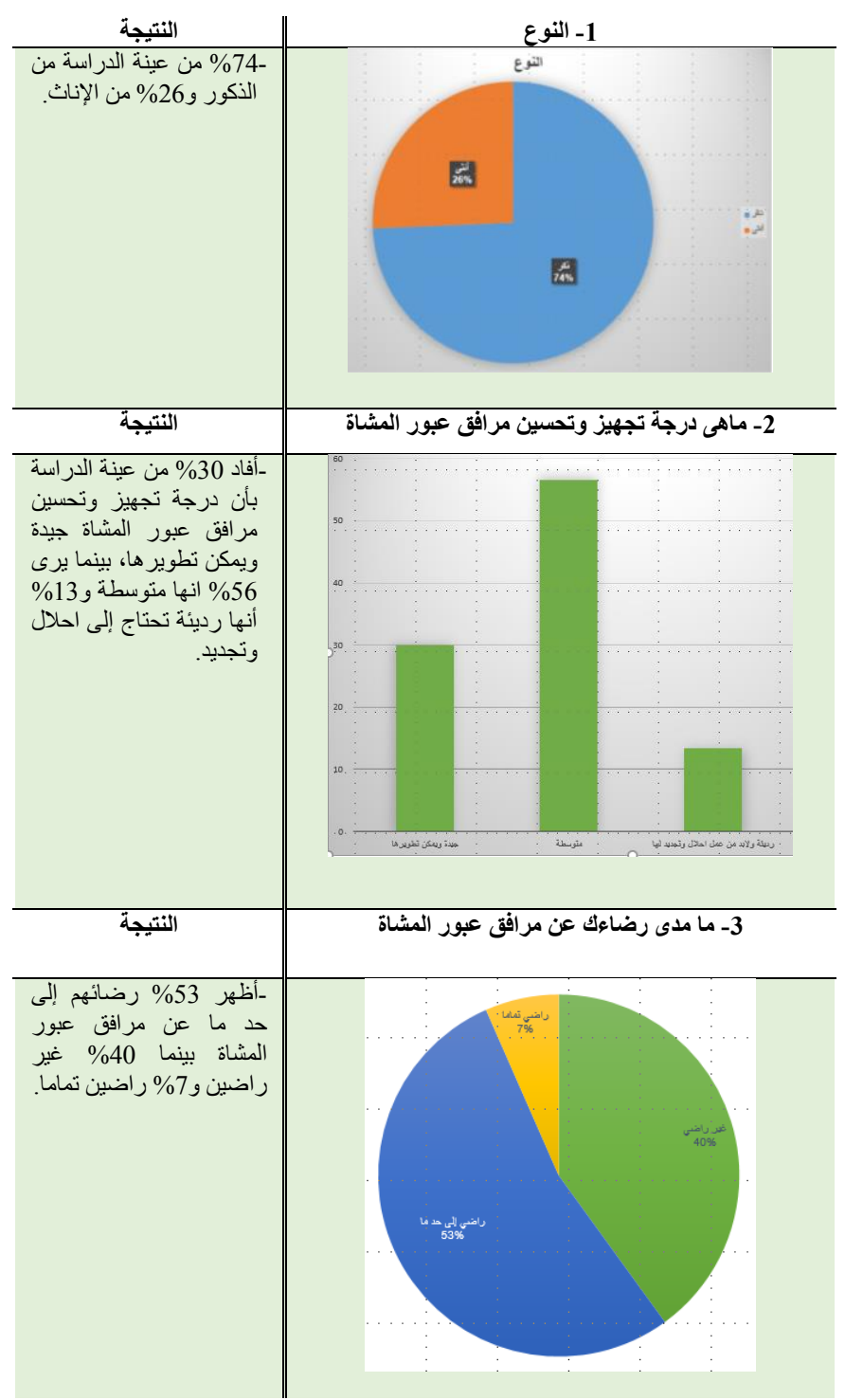




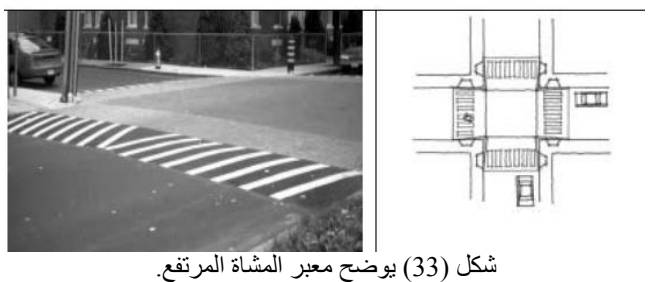

Midblock Crossings 区 هي المعابر التي تكون في منتصفات الطرق أو الأماكن التي يحتاج المشاة

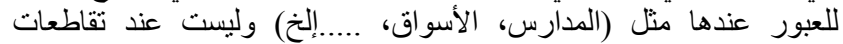

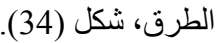

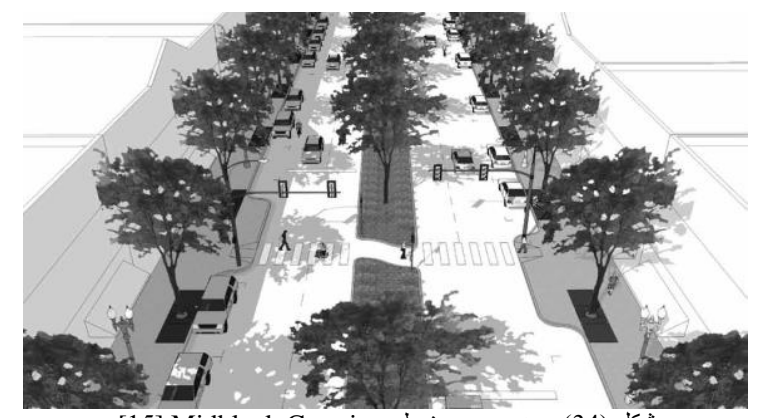

[15] Midblock Crossings شكل (34) يوضح معبر بنمط

\section{AUthors CONTRIBUTION}

1. Conception or design of the work (50/50)

2. Data collection and tools $(\mathbf{5 0 / 5 0})$

3. Data analysis and interpretation (50/50)

4. Funding acquisition (50/50)

5. Investigation $(\mathbf{5 0 / 5 0})$

6. Methodology (50/50)

7. Project administration (50/50)

8. Resources $(\mathbf{5 0 / 5 0})$

9. Software $(50 / 50)$

10. Drafting the article $(\mathbf{5 0 / 5 0})$

11. Critical revision of the article $(50 / 50)$

12. Final approval of the version to be published $(50 / 50)$

\section{REFERENCES}

Available: منظمة الصحة العالمية، الاصدابات الناجمة عن حوادث المرور، https://www.who.int/ar/news-room/fact-sheets/detail/road-traffic-

كريستوفر كوست وأخرون، الشوارع للمشي وركوب الدراجات، برنامج الأمم المتحدة

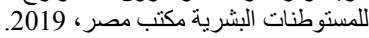

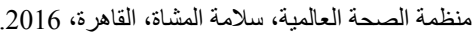
الهيئة العليا لتطوير مدينة الرياض، الدليل الإرشادي للتصميم العمراني لمدينة الرياض، التهاء السعو دية، السئة 2017. [5] وزارة الثئون البلدية، دليل التصميم الهندسي للطرق، السعودية، Aban 2019.

[6] Abu Dhabi urban street design manual. Abu Dhabi, Abu Dhabi Urban Development Council, 2010. Available: https://nelsonnygaard.com/wpcontent/uploads/2014/04/Abu-Dhabi-StreetDesignManual.pdf

[7] Chen Y et al. Safety improvement practice for vulnerable road users in Beijing intersections.TRB 88th Annual Meeting Compendium of Papers DVD. Washington DC, Transportation Research Board, 2008. Available: https://trid.trb.org/view/881412

[8] https://earth.google.com, access at 23/1/2021

[9] Mutto M, Kobusingye OC, Lett RR. The effect of an overpass on pedestrian injuries on a major highway in Kampala - Uganda. African
• أما من حيث تجهيزات البنية التحتية للمعبر فتوجد عدة اتجاهات على النحو

Closed Crossings $\mathbf{X}$

نمط من معابر المشاة تسمح بعبور المشاة في مستوى جميع أذرع التقاطع التارع

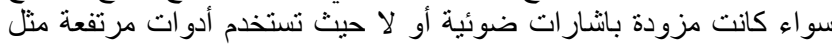

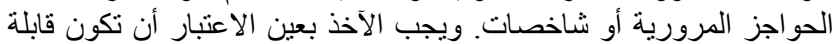
للكثف من قبل المشاة المكفوفين المستخدمين للعصا، شكل (30).

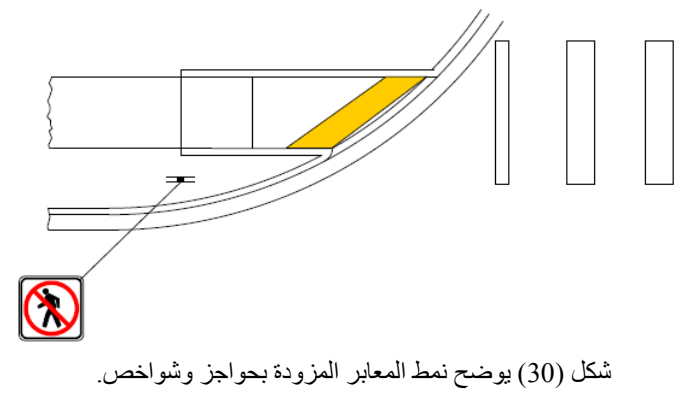

Zebra Crossings 区

نمط من المعابر غير منظم بإنشارات ضوائية ويعطي الأولوية للمشاة لعبور

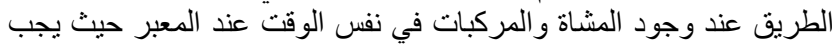

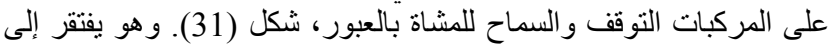

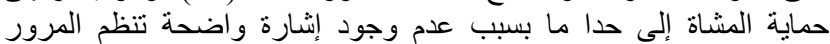
وينطلب درجة كبيرة من الوعي المروري لدى المشاة وقائدي المركبات.

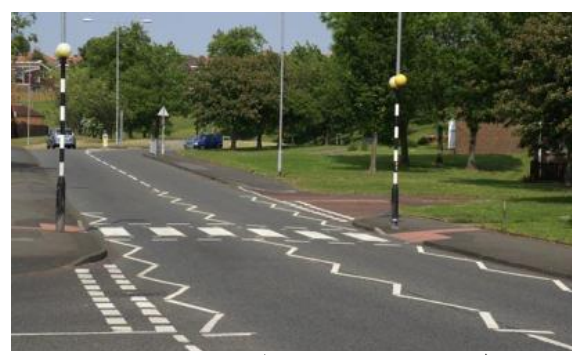

شكل (31) يوضح معبر بنمط Zebra Crossings

Pelican Crossings 冈

احد أكثر الأنماط انتشارا حيث بستند على اعطاء الأولوية للمركبات لتقليل تأخرها بينما يقوم المشاة بطلب العبور من خلال زر طلب العبل العبور ( Push

.(Button

Puffin Crossings 冈

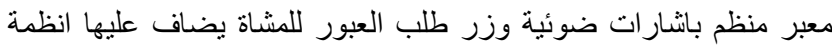

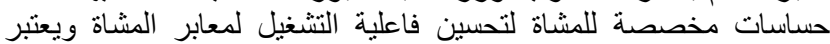

تطوير وتحسين لنمط (Pelican Crossings)، شكل (32) فئن [4] 5] 


\section{Arabic Title}

$$
\begin{aligned}
& \text { معابر مشاة آمنه كأداة لرفع جودة الحياة للمناطق الحضرية } \\
& \text { (در اسة حالة شار ع الهرم) }
\end{aligned}
$$

\section{Abstract Arabic}

المشاة هم النواة الاساسية التي تستخدم الطريق، إلا أن الاهتمام بهم لم يبرز كمؤشر

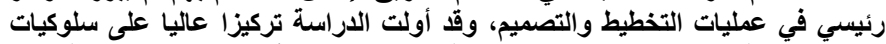

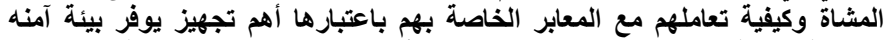

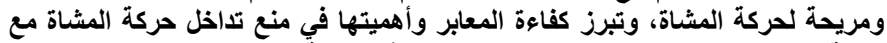

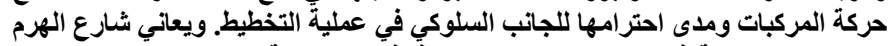

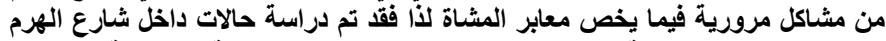

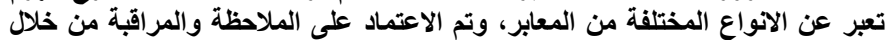

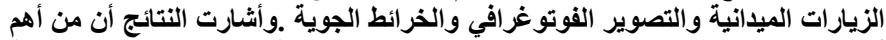

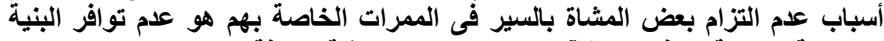

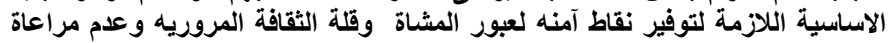
المصمم للجانب السلوكي للمشاة بالاضافة لعدم وجود قو انين رادعة للمخافة للمالفين.
Health Sciences, 2002, 2: 89-93. Available: https://pubmed.ncbi. nlm.nih.gov/ 12789091/

[10] Sietchiping R, Permezel MJ, Ngomsi C. Transport and mobility in subSaharan African cities: an overview of practices, lessons and options for improvement. Cities, 2012, 29:183-189. Available: https://www.infona. $\mathrm{pl} /$ resource/bwmeta1.element.elsevier-9f7885fd-8d4b-30a9-8f5d7 fe $5 \mathrm{~b} 6 \mathrm{~d} 5 \mathrm{e} 1 \mathrm{cf}$

[11] Tiwari G, et al. Survival analysis: pedestrian risk exposure at signalized intersections. Transportation Research ,Part F, 2007, Available: http://www.vref.se/download/18.6a462c7912efb9dc85f80004547/2007+ Tiwari.pdf

[12] Zegeer CV, Bushell M. Pedestrian crash trends and potential countermeasures from around the world. Accident Analysis \& Prevention, 2012, 44: 3-11, Available: https://pubmed.ncbi.nlm.nih.gov /22062330/

[13] Michael F.Trentacoste, Pedestrian Facilities Users Guide- Providing Safety and Mobility, U.S. Department of Transportation, 2002, Available:https://www.fhwa.dot.gov/publications/research/safety/01102/ 01102.pdf

[14] Sitti Asmah Hassan, Improving Pedestrian Facilities At Signalised Crossings, UNIVERSITY OF SOUTHAMPTON, 2013, Available: https://eprints.soton.ac.uk/355891/1/Improving\%2520Pedestrian\%2520 Facilities\%2520At\%2520Signalised\%2520Crossings.pdf

[15] Institute of Transportation Engineers, Design Walkable Urban Thoroughfares A Context Sensitive Approach, 2010 